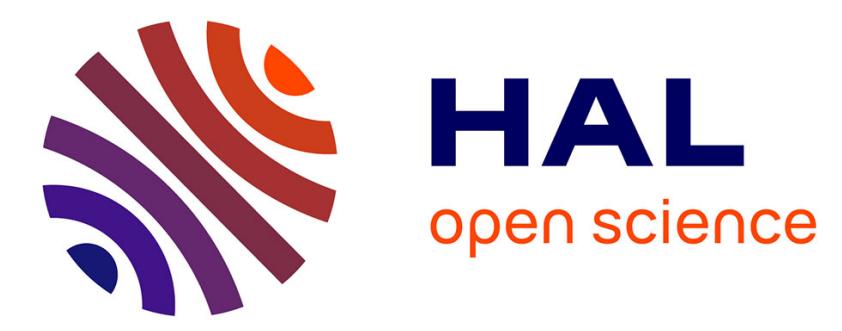

\title{
Plasmon electron energy loss spectroscopy and electrical resistivity of AlMn and AlMnSi quasicrystalline phases
} Jean-Louis Verger-Gaugry, Pierre Guyot, Marc Audier

\section{To cite this version:}

Jean-Louis Verger-Gaugry, Pierre Guyot, Marc Audier. Plasmon electron energy loss spectroscopy and electrical resistivity of AlMn and AlMnSi quasicrystalline phases. Physics Letters A, 1986, 117 (6), pp.307-312. 10.1016/0375-9601(86)90395-6 . hal-03136743

\section{HAL Id: hal-03136743 \\ https://hal.science/hal-03136743}

Submitted on 13 Feb 2021

HAL is a multi-disciplinary open access archive for the deposit and dissemination of scientific research documents, whether they are published or not. The documents may come from teaching and research institutions in France or abroad, or from public or private research centers.
L'archive ouverte pluridisciplinaire HAL, est destinée au dépôt et à la diffusion de documents scientifiques de niveau recherche, publiés ou non, émanant des établissements d'enseignement et de recherche français ou étrangers, des laboratoires publics ou privés. 


\title{
PLASMON ELECTRON ENERGY LOSS SPECTROSCOPY AND ELECTRICAL RESISTIVITY OF AIMn AND AIMnSi QUASICRYSTALLINE PHASES
}

\author{
J.-L. Verger-Gaugry, P. Guyot and M. Audier
}

LTPCM/ENSEEG/INPG (CNRS UA 29), BP 75, Domaine Universitaire, 38402 Saint Martin d'Hères, France

\begin{abstract}
The electrical resistivity of the icosahedral and decagonal phases is investigated in AlMn and AlMnSi meltspun ribbons by means of EELS in a dedicated STEM. The RT-resistivity of the i-phase is reported to be $66 \mu \Omega \mathrm{cm}$ and is controlled essentially by the solute content. The intrinsic effect due to the quasiperiodic distribution of the $\mathrm{Mn}$ scatterers is weak.
\end{abstract}




\section{Introduction}

The icosahedral phase (i-phase) in AlM (M = $\mathrm{Mn}, \mathrm{Cr}$ ) with long-range orientational order and five-fold point group symmetry was initially produced by rapid quenching from the melt in the composition range 10-4 at\% $\mathrm{M}$ [1]; it coexists then with a residual crystalline foc $\alpha$-Al matrix, being formed through a nucleation and growth mechanism characteristics of a first-order transformation. However, the size of these quasicrystals exceeds rarely a few microns which renders difficult the determination of their physical properties, those which normally are characterized in a "macroscopic" way.

In this extent, analytical techniques in a scanning transmission electron microscope (STEM) appear well suited to their investigation. For instance, they provide an insight to the local solute (M) concentration by X-ray EDS, which is essential for heterogeneous specimens.

Another analytical STEM technique is the electron energy loss spectroscopy (EELS). We use it presently to study the plasmon losses in quasicrystals (i- and decagonal or T-phase [2]) and crystals of the same composition in melt-spun AlMn and AlMnSi.

From the position and full width at half maximum (FWHM) of the bulk plasmon, we deduce an estimate of the "microscopic" resistivity on the scale of the electron beam diameter, as has been done before small $\mathrm{Al}$ particles [3], and glassy metals [4].

\section{Experimental}

\subsection{Materials}

Quasicrystals in melt-spun $\mathrm{Al}_{86} \mathrm{Mn}_{14}, \mathrm{Al}_{80} \mathrm{Mn}_{20}$ and $\mathrm{Al}_{74} \mathrm{Mn}_{20} \mathrm{Si}_{6}$ have been investigated. The iphase coexists with the $\alpha-\mathrm{Al}$ matrix in $\mathrm{Al}_{86} \mathrm{Mn}_{14}$, with the decagonal or $\mathrm{T}$-phase (2) in $\mathrm{Al}_{80} \mathrm{Mn}_{20}$; in $\mathrm{Al}_{74} \mathrm{M}_{20} \mathrm{Si}_{6}$, a few crystals (volume fraction less than $10 \%)$ of the cubic $\alpha(\mathrm{AlMnSi})$-phase $[5,13]$ ean be found in addition to the i-phase and the $\alpha$-Al matrix.

In order to characterize the corresponding crystallized compounds, $\mathrm{Al}_{86} \mathrm{M}_{14}$ ribbons were annealed at $550^{\circ} \mathrm{C}$ during $70 \mathrm{~h}$ under vacuum and $\mathrm{Al}_{80} \mathrm{Mn}_{20}$ ribbons at $1050^{\circ} \mathrm{C}$ during one hour. In the first case, an orthorhombic phase is formed and occupies almost all the ribbon. It corresponds to $\mathrm{Al}_{6} \mathrm{Mn} \mathrm{[6].} \mathrm{In} \mathrm{the} \mathrm{second} \mathrm{case,} \mathrm{the} \mathrm{T}$. and i-phases transform into a hexagonal phase [7].

Ribbons were selectively etched to remove the residual matrix supersaturated in manganese (fig. $1)$.

After electropolishing the ribbons using the electrolyte D12 Struers at $-30^{\circ} \mathrm{C}$ under $20 \mathrm{~V}$, thin foils were observed and analyzed in a vacuum-generator HB 501 scanning transmission 


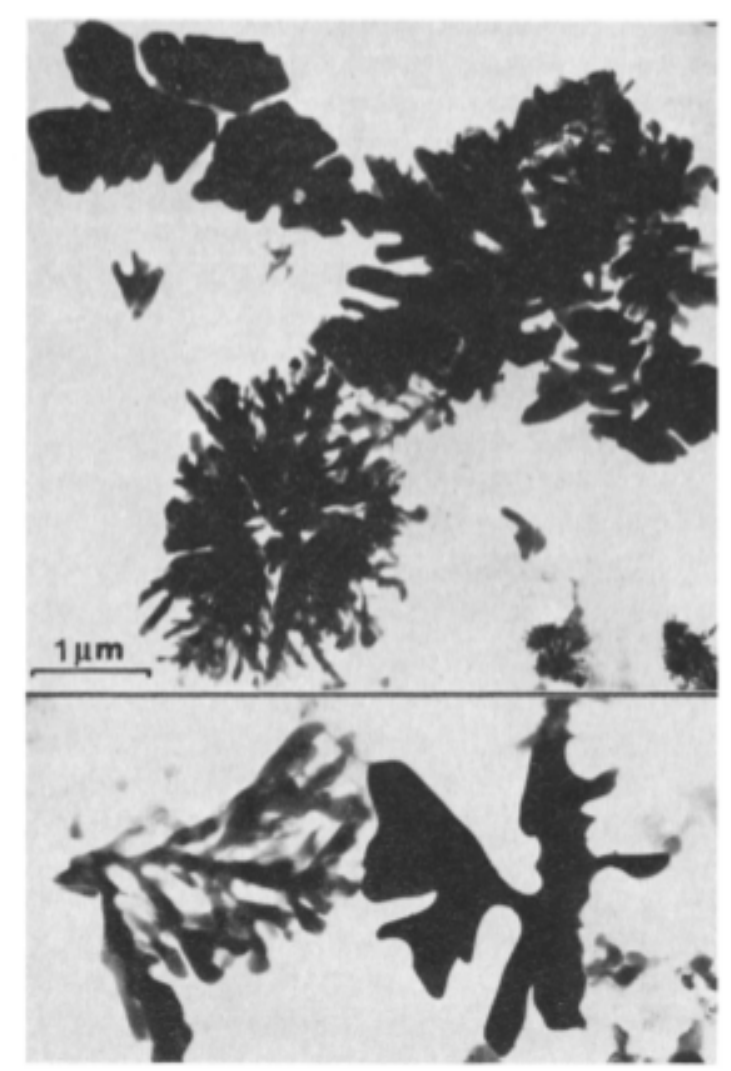

Fig. 1. Transmission electron micrography of i-phase particle: (bright field image). electron microscope (STEM) equipped with a field-emission gun and a Tracor Northern TN $2000 / 4000$ microcomputer.

X-Ray EDS analysis was systematically performed in the regions which were investigated by EELS in order to keep as far as possible an actual correspondence between the composition and the EEL spectra. Each phase analyzed was extensively tested and values given in table 1 provide reliable averages over numerous localized analysis.

Pure $(99.97 \%)$ aluminium was also tested to serve as a reference for bulk plasmon energy, energy width and resistivity.

The determination of the $\mathrm{Mn}$ and $\mathrm{Si}$ concentration was performed by $\mathrm{X}$-ray EDS using the $\mathrm{Si}, \mathrm{Al}$ and $\mathrm{Mn} \mathrm{K} \alpha$ lines and the classical ratio method for which the Cliff-Lorimer constants $k_{\mathrm{AIMn}}, k_{\mathrm{AISi}}$ were previously determined to be 0.766 and 0.882 respectively. Absorption corrections, when carried out, modified only slightly the results.

\subsection{STEM operating conditions for EELS analysis}

The STEM was operated under conditions minimizing the instrumental broadening of the plasmon loss peaks, i.e. with minimum probe semi-angle of convergence $\alpha_{\mathrm{i}}$ and minimum semiangle of collection $\theta_{\mathrm{i}}$.

The following data collection conditions were

Table 1

Plasmon energy loss data, resistivity $\rho$ and relaxation time $\tau$ from the bulk plasmon energy and its FWHM. $N_{\mathrm{Mn}}$ represents the number of conduction electrons brought per atom $\mathrm{Mn}$.

\begin{tabular}{|c|c|c|c|c|c|c|c|c|}
\hline Alloy & Phase & $\begin{array}{l}C_{\mathrm{Mn}} \\
\text { (at\%) }\end{array}$ & $\begin{array}{l}\delta E \\
(\mathrm{eV})\end{array}$ & $\begin{array}{l}E_{\mathrm{p}} \\
(\mathrm{eV})\end{array}$ & $\begin{array}{l}\Delta E_{1 / 2} \\
(\mathrm{eV})\end{array}$ & $\begin{array}{l}\rho \\
(\mu \Omega \mathrm{cm})\end{array}$ & $\begin{array}{l}\tau \times 10^{15} \\
\text { (s) }\end{array}$ & $\begin{array}{l}N_{\mathrm{Mn}} \\
\left(e^{-} / \text {atom Mn) }\right.\end{array}$ \\
\hline Al & $\alpha-\mathrm{Al}$ & 0 & 0.50 & 14.95 & 0.71 & $24 \pm 20^{\text {a) }}$ & 0.93 & 0 \\
\hline \multirow[t]{2}{*}{$\mathrm{Al}_{96} \mathrm{Mn}_{14}$} & $\alpha \cdot \mathrm{Al}$ matrix & 3.1 & 0.67 & 15.20 & 0.75 & $24 \pm 20$ & 0.88 & 6.2 \\
\hline & i & 20.0 & 0.54 & 16.33 & 2.35 & $66 \pm 29$ & 0.28 & 5.9 \\
\hline $\mathrm{Al}_{80} \mathrm{Mn}_{20}$ & $\mathrm{~T}$ & 20.0 & 0.61 & 15.59 & 1.91 & $58 \pm 26$ & 0.35 & 4.3 \\
\hline $\begin{array}{l}\mathrm{Al}_{80} \mathrm{Mn}_{20} \\
\quad+1050^{\circ} \mathrm{C} / 1 \mathrm{~h}\end{array}$ & hex. & 20.0 & 0.61 & 16.12 & 2.32 & $66 \pm 30$ & 0.28 & 5.4 \\
\hline $\begin{array}{l}\mathrm{Al}_{86} \mathrm{Mn}_{14} \\
\quad+550^{\circ} \mathrm{C} / 70 \mathrm{~h}\end{array}$ & orth. & $14 \pm 4$ & 0.57 & 15.76 & 1.71 & $51 \pm 21$ & 0.38 & 4.6 \\
\hline \multirow{2}{*}{$\begin{array}{l}\mathrm{Al}_{74} \mathrm{Mn}_{20} \mathrm{Si}_{6} \\
\text { (ternary) }\end{array}$} & $\alpha$-Al matrix & $1.8+0.4$ & 0.60 & 15.04 & 0.70 & $23 \pm 20$ & 0.94 & $<5.0$ \\
\hline & i & 19.5 & 0.64 & 16.46 & 2.48 & $68 \pm 25$ & 0.26 & $<6.3$ \\
\hline
\end{tabular}

*) The four-point method gives around $2.63 \mu \Omega \mathrm{cm}$ at $293 \mathrm{~K}$. 
used: (i) incident electron energy, $E_{0}=100 \mathrm{keV}$ (electron wavelength, $\lambda=0.037 \AA$ ); (ii) probe semi-angle of convergence, $\alpha_{i}=1.13 \mathrm{mr}$; (iii) semi-angle of collection, $\theta_{\mathrm{i}}=0.7 \mathrm{mr}$; giving rise to a probe diameter of $\approx 43 \AA$, and a maximum scattering vector $q_{\max }=(2 \pi / \lambda)\left(\alpha_{i}+\theta_{i}\right)=0.311$ $\AA^{-1}$ in the case of single scattering events.

\section{Bulk plasmon loss and electrical resistivity}

In a free electron gas, the plasmon loss is characterized by its position:

$E_{\mathrm{p}}=h \omega_{\mathrm{p}}=h\left(n e^{2} / m \epsilon_{0}\right)^{1 / 2}$,

with $n$ the electron density, $\epsilon_{0}$ the permittivity of free space, and the FWHM of the loss function $\Delta E_{1 / 2}=h \tau^{-1}, \tau$ being the plasmon oscillation life time. The electrical resistivity can then be formulated by

$\rho=m / n e^{2} \tau=\left(h / \epsilon_{0}\right) \Delta E_{1 / 2} /\left(E_{\mathrm{p}}\right)^{2}$, if one makes the assumption that the relaxation time is equal to the plasmon life time.

Examples of EEL spectra obtained on the AIMn $\mathrm{i}$-phase and the residual $\alpha$-Al matrix in the meltspun $\mathrm{Al}_{86} \mathrm{Mn}_{14}$ ribbon are shown in fig. 2 .

The loss function is normally obtained after deconvoluting the experimental spectra from multiple scattering, surface contributions, and energy and angular integration. No full deconvolution of the spectra was performed, but care was taken to record EEL spectra from thin parts of the samples in order to minimize multiple scattering. We have developed a procedure, which can be viewed as a first-order energy and angular deconvolution. Using the dispersion relations $[8,9]$, to first order:

$h \omega_{\mathrm{p}}(q)=h \omega_{\mathrm{p}}+\alpha\left(h^{2} / m\right) q^{2}$,

$\Delta E_{1 / 2}(q)=\Delta E_{1 / 2}+\alpha_{1 / 2}\left(\hbar^{2} / m\right) q^{2}$,

one can easily show, assimilating the energetic gaussian distribution of the electron beam to a crenel function of the same width $\delta E(\approx 0.5 \mathrm{eV})$,

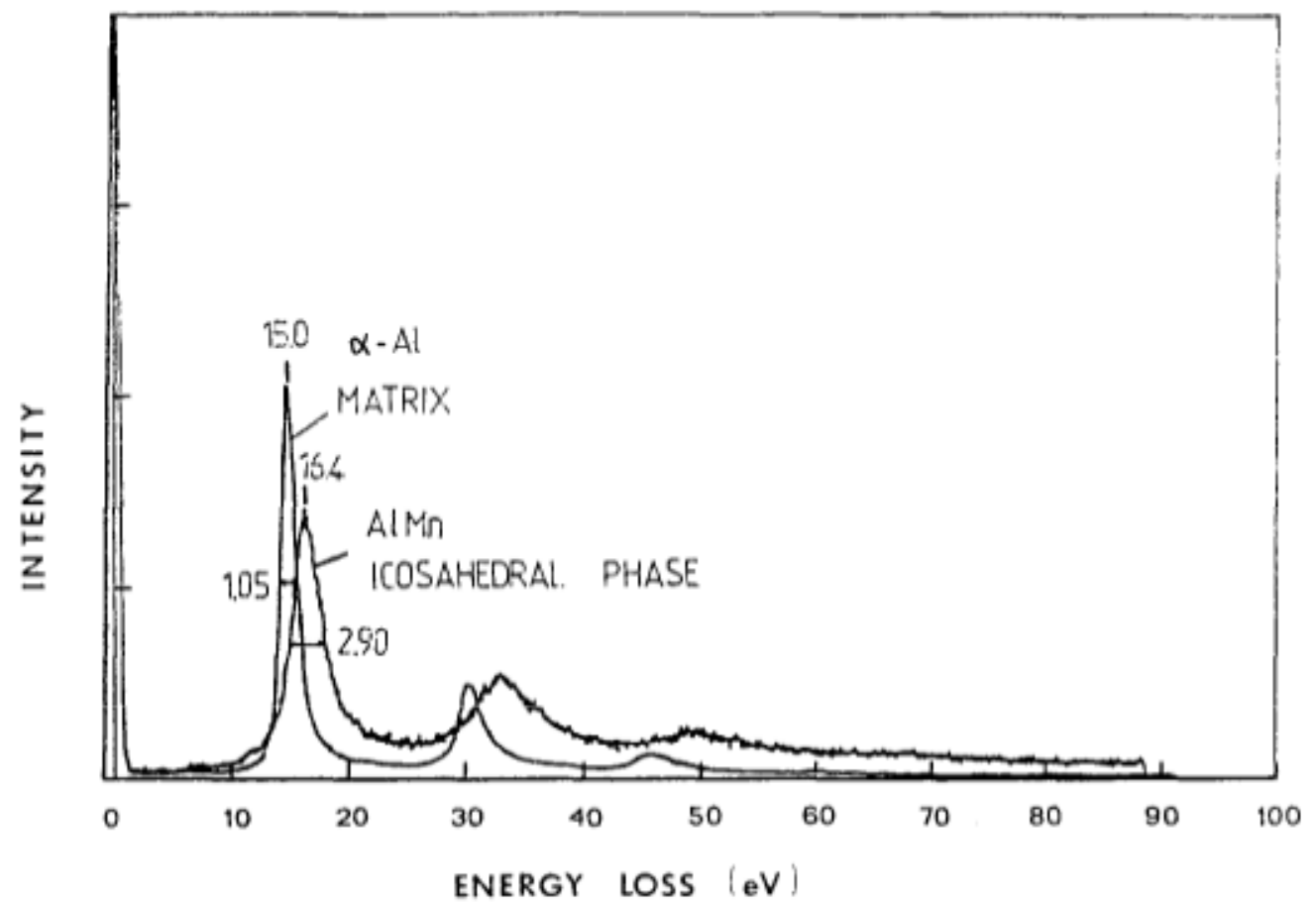

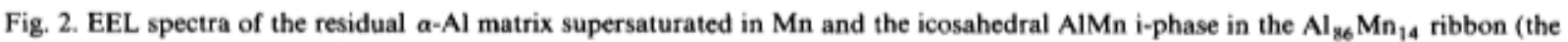
acquisition conditions are reported in the text). The measured values of $E_{\mathrm{p}}$ and $\Delta E_{1 / 2}$, in $\mathrm{eV}$, are indicated. 
that:

$E_{\mathrm{p}}=E_{\mathrm{p}}^{\mathrm{mes}}-\frac{1}{2} \alpha\left(\hbar^{2} / m\right) q_{\max }^{2}$,

$\Delta E_{1 / 2}=E_{1 / 2}^{\text {mes }}-\frac{1}{2} \delta E-\left(\frac{1}{2} \alpha+\frac{1}{4} \alpha_{1 / 2}\right)\left(\hbar^{2} / m\right) q_{\max }^{2}$.

The upper and lower bounds of $E_{\mathrm{p}}$ and $\Delta E_{1 / 2}$ are given by

$E_{\mathrm{p}} \pm\left(\frac{1}{2} \delta E+\frac{1}{2} \alpha\left(\hbar^{2} / m\right) q_{\max }^{2}\right)$,

$\Delta E_{1 / 2} \pm\left[\frac{1}{2} \delta E+\left(\frac{1}{2} \alpha+\frac{1}{4} \alpha_{1 / 2}\right)\left(h^{2} / m\right) q_{\max }^{2}\right]$.

The dispersion of the results is small compared to the uncertainties related to the above deconvolution procedure. We must notice that pure $\mathrm{Al}$, with a theoretical $\Delta E_{1 / 2}$ of the order of the energy resolution $\delta E$, is at the limit of applicability of the method.

Finally one can consider that these results are acquired at room temperature, for the unknown local heating by the electron beam is probably negligible.

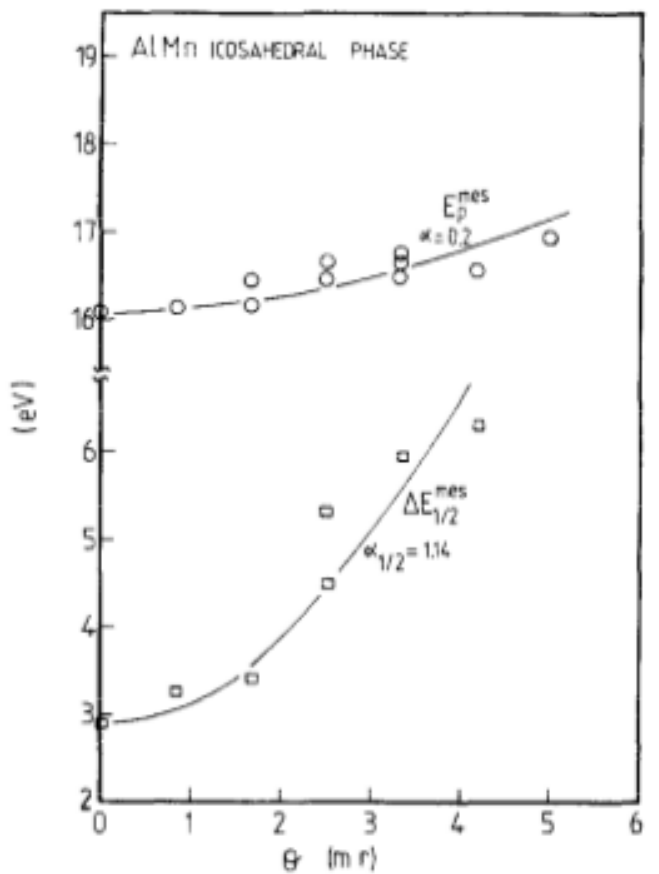

Fig. 3. Dispersion relations for the bulk plasmon energy and energy width of the i-AIMn phase. The scattering angle $\theta$ and wave vector $q$ are related by $q=170 \dot{\AA}^{-1} \theta$.
The constants $\alpha$ and $\alpha_{1 / 2}$ were determined in the case of the AlMn i-phase by means of the post-spectrum deflection coils (fig. 3). These constants were supposed to be identical for the other AlMn phases. We report $\alpha=0.20$ and $\alpha_{1 / 2}=1.14$. For aluminium, these constants were taken from refs. [8,10]: $\alpha=0.15$ and $\alpha_{1 / 2}=0.17$.

\section{Results and discussion}

The results of the bulk plasmon energy and FWHM measurements are given in table 1, as well as the corresponding relaxation times and resistivities calculated by the procedure described above. The EELS characteristics of the i-phase in both $\mathrm{Al}_{86} \mathrm{Mn}_{14}$ and $\mathrm{Al}_{80} \mathrm{Mn}_{20}$ ribbons are identical.

Fig. 4 shows the variations of the plasmon loss $E_{\mathrm{p}}$ and its FWHM $\Delta E_{1 / 2}$ with the Mn content of the various phases investigated.The resulting variations of the resistivity are plotted in fig. 5 .

\subsection{Bulk plasmon energy}

In all the binary phases, the bulk plasmon energy loss increases with the Mn content (fig. 4a). This increase was already observed by X-ray induced photoemission spectroscopy (XPS) by Steiner et al. on coevaporated AlMn alloys [11]. Although the state of these alloys, either amorphous or crystalline, has not been specified. they may serve nevertheless as a reference for rapidly quenched AlMn alloys. Steiner et al.'s data are plotted in fig. $4 \mathrm{a}$. It may be noted that a continuity of their data with those relative to the i-phase occurs. If we assume that the alloys investigated by Steiner et al. are amorphous, which is usually the case for codeposition, one can conclude that the plasmon loss is not very sensitive to the long-range orientational order of the i-phase and depends essentially, like in the disordered state, upon the density of Mn scatterers.

The following free electron density for the iphase, deduced from eq. (1) of the bulk plasmon loss is $1.95 \times 10^{29} \mathrm{~m}^{-3}$. If $N_{\mathrm{Mn}}$ is the number of conduction electrons brought per $\mathrm{Mn}$ atom, the plasmon loss can be written

$E_{\mathrm{p}}=E_{\mathrm{p}}(\mathrm{Al})\left[1+\frac{1}{3} C\left(N_{\mathrm{Mn}}-3\right)\right]^{1 / 2}$, 


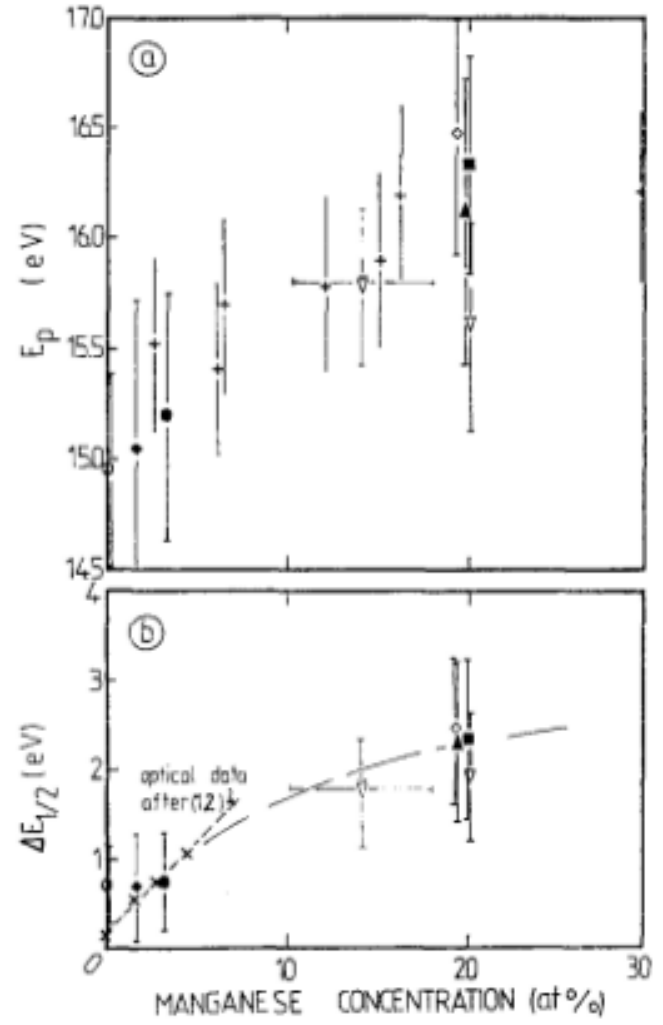

Fig. 4. (a) Bulk plasmon energy and (b) FWHM of the bulk plasmon versus the atomic $\mathrm{Mn}$ content in the various phases investigated. Data on coevaporated AIMn alloys: (+) ref. [11], $(x)$ ref. [12].

where $C$ is the atomic Mn concentration. Under this assumption, $N_{\mathrm{Mn}}$ is equal to 5.9 electrons in the i-phase. Contributions of Mn to the electron density for each phase are reported in table 1 .

When comparing the EELS characteristics of the T- and i-p! ases, one can observe that atomic structure and isn concentration act in a synergetic way on the unduction electron density, through $E_{\mathrm{p}}$, and on the relaxation time $\tau$, through $\Delta E_{1 / 2}$, although ea:h effect mutually compensates to give rise to small variations of the resistivity.

In the ternary ribbons, large $\mathrm{Si}$ concentration fluctuations were observed, in the i-phase as well as in the $\alpha$ - $\mathrm{Al}$ matrix (from 7.8 to 15.5 at $\%$ and 0 to 11.0 at\%, respectively) whereas these two phases are fairly homogeneous in $\mathrm{Mn}$.

Using eq. (9) and neglecting the $\mathrm{Si}$ content

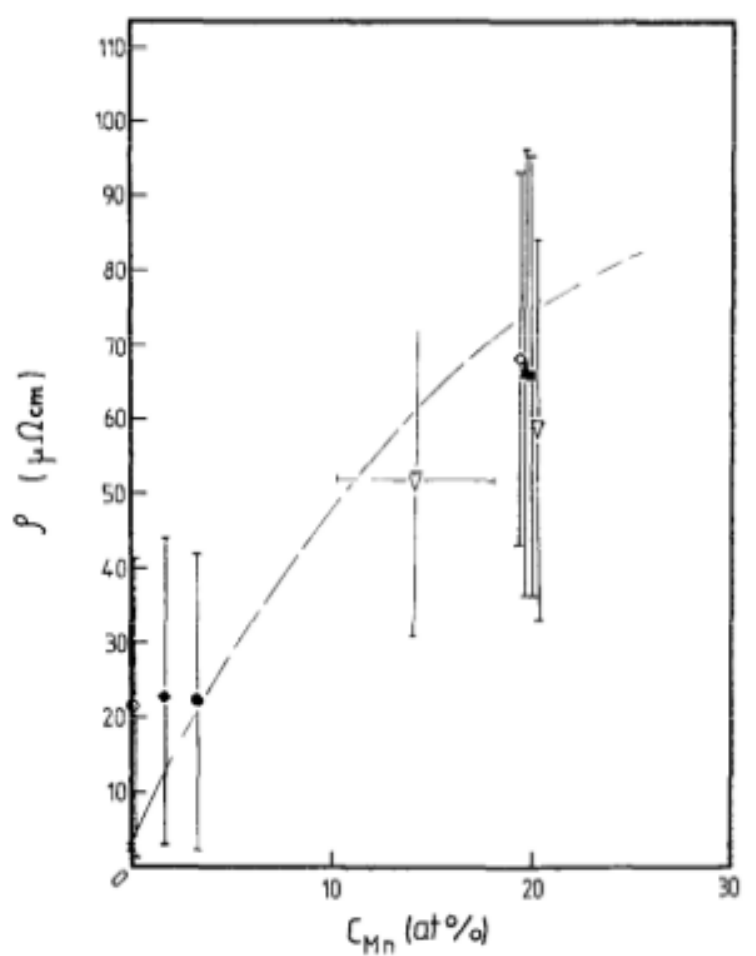

Fig. 5. Electric resistivity of the AlMn quasicrystals (i- and T-phases) and the periodic AlMn-AIMnSi phases versus the atomic manganese content.

gives an upper bound for $N_{\mathrm{Mn}}, 5.0$ and $6.3 \bar{e}$ per $\mathrm{Mn}$ atom respectively, in good agreement with the data on the binary alloys.

\subsection{Energy width and resistivity}

The inverse of the relaxation time increases with the Mn concentration in the various phases investigated, as shown in fig. 4b. A linear increase was already observed by optical measurements on coevaporated alloys for concentrations less than 5 at\% Mn, by Beaglehole and Wihl [12]. Their data, expressed in terms of plasmon energy loss width, are reported in fig. $4 \mathrm{~b}$; expect for pure $\mathrm{Al}$, they fit fairly well our results for the $\mathrm{Al} \alpha$-phase.

For all the binary AIMn phases investigated, the general behaviour of the resistivity is to increase with the $\mathrm{Mn}$ content, as is the case for the FWHM $\Delta E_{1 / 2}$, in a semi-quantitative agreement 
with a parabolic Mathiessen rule with $\delta_{\mathrm{Mn}}=612$ $\mu \Omega \mathrm{cm}(6)$.

Furthermore, the resistivity values of all the phases containing approximately 20 at $\% \mathrm{Mn}$ do not differ strongly (fig. 5, table 1) except for the T-phase resistivity which is slightly lower. This small dispersion shows that the prominent effect on the relaxation time is the Mn content, whatever the solute is distributed periodically, as in the hexagonal phase, or aperiodically in the i-phase.

The resistivity of the i-phase appears to be almost identical in AIMnSi and AIMn (68 and 86 $\mu \Omega \mathrm{cm}$ ). This result is coherent with the small expected effect of $\mathrm{Si}$, which residual resistivity [6] is small as compared to that of $\mathrm{Mn}$.

The $\alpha(\mathrm{AlMnSi})$-phase [13] was identified by CTEM but it was impossible to obtain EEL spectra which could be attributed unambiguously to this phase, for it is always too intimately mixed with the i-phase.

At the scale of the electron probe (a few nm), the contribution of structural defects and interfaces is negligible. It is normally taken into account in the four-terminal de technique and should be deduced from the measurements. The dendritic morphology of the T- or i-phase as well as the presence of microcracks generated in ribbons by the melt-spinning process make this method insufficiently reliable as compared to EELS local investigations in a STEM.

\section{Conclusion}

The EELS-study in a (STEM) scanning transmission electron microscope is a powerful technique to determine local electronic properties in the range of plasmon losses. Though EEL-spectra deconvolution was processed only to first-order to obtain the loss function, the method provides usefull estimates of the resistivity of the Mn-rich phases.

It appears that the Mn content controls essentially the resistivity at room temperature. The weak variations of the RT-resistivity between crystalline and quasicrystalline phases demonstrate that the spatial distribution of the strong Mn scatterers has only a second-order effect. within the overall compositions studied. However, synergetic effects between structure and $\mathrm{Mn}$ concentration are observed in the bulk plasmon energy and its FWHM.

\section{References}

[1] D. Shechtman, I. Blech, D. Gratias and J.W. Cahn, Phys. Rev. Lett. 53 (1984) 1951.

[2] L. Bendersky, Phys, Rev, Lett. 55 (1985) 1461.

[3] P.E. Batson, Solid State Commun. 34 (1980) 477.

[4] 1.M. Reda, P. Schattschneider, K. Riedl, A. Wagendristel. H. Bangert and F. Gautier, Thin Solid Films 116 (1984) 269.

[5] P. Guyot and M. Audier, Philos. Mag. B 52 (1985) L.15.

[6] L.F. Mondolfo, Aluminum alloys: structure and properties (Butterworths, London, 1976).

[7] W. Hofmann, Aluminium (Berlin) 20 (1938) 865.

[8] H. Raether. Excitation of plasmons and interband transitions by electrons (Springer, Berlin, 1980).

[9] M. Hasegawa, J. Phys. Soc. Japan 31 (1971) 649.

[10] C.V. Festenberg. Z. Phys. 207 (1967) 47.

[11] P. Steiner, H. Hoechst, W. Steffen and S. Huefner, Z Phys. B 38 (1980) 191.

[12] D. Beaglehole and M. Wihl, J. Phys. F. 2 (1972) 43.

[13] M. Cooper, K. Robinson, Acta Cryst. 20 (1966) 614; M. Audier and P. Guyot, Philos. Mag. B 53 (1986) L.43. 